DEMOGRAPHIC RESEARCH

VOLUME 34, ARTICLE 20, PAGES 563-586

PUBLISHED 23 MARCH 2016

http://www.demographic-research.org/Volumes/Vol34/20/

DOI: 10.4054/DemRes.2016.34.20

Research Article

Diverging patterns of fertility decline in Uruguay

Mathias Nathan

Ignacio Pardo

Wanda Cabella

(C) 2016 Mathias Nathan, Ignacio Pardo \& Wanda Cabella.

This open-access work is published under the terms of the Creative Commons Attribution NonCommercial License 2.0 Germany, which permits use, reproduction \& distribution in any medium for non-commercial purposes, provided the original author(s) and source are given credit.

See http://creativecommons.org/licenses/by-nc/2.0/de/ 


\section{Table of Contents}

1 Introduction $\quad 564$

2 Background 565

$3 \quad$ Data and measures $\quad 568$

$4 \quad$ Results 570

4.1 Trends in quantum and tempo of fertility by birth order 570

4.2 Conditional ASFR by birth order in Uruguay 574

4.3 MAB1 and sdMAB1 in Uruguay and selected countries 576

5 Conclusions $\quad 579$

6 Acknowledgements 581

References $\quad 582$

$\begin{array}{ll}\text { Appendix } & 586\end{array}$ 


\title{
Diverging patterns of fertility decline in Uruguay
}

\author{
Mathias Nathan ${ }^{1}$ \\ Ignacio Pardo ${ }^{2}$ \\ Wanda Cabella ${ }^{3}$
}

\begin{abstract}
BACKGROUND

The total fertility rate (TFR) in Uruguay fell from 2.5 to 1.9 children per woman between 1996 and 2011. However, no study to date has examined the decline of the TFR by observing changes in fertility patterns by birth order.
\end{abstract}

\section{OBJECTIVE}

The main aim of this study is to analyze recent changes in fertility level and timing of childbearing by birth order in Uruguay.

\section{METHODS}

We estimate unconditional and conditional age- and birth-order-specific fertility rates for 1996-2011 using data from vital statistics, population census, and national population estimates. Additionally, three period summary measures of birth-orderspecific fertility quantum are calculated: TFR, PATFR and TFRp*. Timing changes by birth order are examined with MAB and TMAB, focusing on MAB1 and its standard deviation and comparing their evolutions in Uruguay with those of selected countries.

\section{RESULTS}

Fertility decline fits a parity-specific stopping model with a moderate increase in the mean ages of first, second, and third births. The distribution of conditional fertility rates for first and second births depicts an asymmetric bimodal shape linked to the increasing heterogeneity of the timing of childbearing. Compared to countries with similar fertility trends, heterogeneity in the age at first birth in Uruguay is remarkably high.

\section{CONCLUSIONS}

Previous studies suggest that heterogeneity in first and second birth timing is related to structural social inequalities, as women from lower social strata have not significantly changed the age at which they bear a first child, whereas women of middle to high

\footnotetext{
${ }^{1}$ Universidad de la República del Uruguay.

${ }^{2}$ Universidad de la República del Uruguay. E-Mail: ignacio.pardo@cienciassociales.edu.uy.

${ }^{3}$ Universidad de la República del Uruguay.
} 
social strata have started to postpone it. The new evidence reinforces the idea that postponement transition in Uruguay cannot be studied without considering this consolidation of social status polarization in fertility timing.

\section{Introduction}

The purpose of this paper is to analyze the changes in the level and timing of fertility in Uruguay between 1996 and 2011, using period fertility measures by birth order. The analysis of the evolution of fertility trends by birth order can contribute to the understanding of the three main processes in the transition towards a low-fertility setting: the reduction of higher-order births through parity-specific fertility control, the increase in the proportion of women who remain childless throughout their reproductive years, and the postponement of childbearing. Each one of these processes is closely related to the others and together they typically cause the decline of the conventional period total fertility rate (TFR).

With some exceptions (Batyra 2015; Miranda-Ribeiro, Rios-Neto, and Ortega 2008; Rios-Neto and Miranda-Ribeiro 2015), the analysis of the recent decline in the TFR in Latin American countries has relied exclusively on data on births by age of the mother. While several European and North American countries have long series of data on birth counts by both age of the mother and birth order, they are rare to find in Latin America countries with the exceptions of Chile, Costa Rica, and - recently - Uruguay (Lima et al. 2015; Rosero-Bixby, Castro-Martin, and Martín García 2009).

For this study we constructed the 1996-2011 series of births by age of the mother and birth order by using individual birth registers from the Live Birth Certificate and the Perinatal Information System of Uruguay, and estimated age- and birth-orderspecific fertility rates and summary measures of timing and quantum of fertility. We analyzed this set of indicators to demonstrate the extent of family limitation, childlessness, and postponement in the evolution of fertility for synthetic cohorts during the recent decline of the period TFR in Uruguay.

Studying fertility by birth order may allow a more rigorous analysis of the demographic components of recent changes in fertility and the construction of new measures will allow the comparison of fertility decline in Uruguay with those of other, mostly European countries.

As seen in several developed countries, a shift in the timing of childbearing can inflate or deflate the conventional period TFR (Bongaarts and Sobotka 2012). In a recent work, Pardo and Cabella (2014) estimated tempo-adjusted (TFR*) and tempoand parity-adjusted (TFRp*) total fertility rates for Uruguay for the years 1996-2011. 
They found that TFR decreased almost entirely by quantum decline, as the tempo effect only accounted for TFR change through a peak in the 3-4 worst years of the economic crisis that hit the country between 1998 and 2004 and a mild increase in the last years. In this paper we also apply tempo-adjusted period fertility indicators to compare their trends with the developments in the conventional period TFR, examining to what extent the two differed over time and how sizeable the recent impact of the tempo effect on Uruguayan TFR is. Furthermore, the use of the tempo- and parity-adjusted measures of quantum fertility by birth order would allow breaking down changes in tempo-adjusted fertility into their birth order components, possibly providing more accurate evidence on the role of parity-specific fertility declines in the observed changes in period fertility.

The structure of the article is as follows. First, it provides some background on fertility decline in Latin America and the Caribbean, and specifically Uruguay. Then, the context of extensive socioeconomic and family change within which it has taken place is discussed. Next, the data and methods used are described and fertility level and timing by birth order are reported, including conditional age-specific fertility rates by birth order and summary measures on both dimensions. Finally, mean age at first birth and its standard deviation in Uruguay is compared with those of other selected countries and some final remarks are made.

\section{Background}

Latin America and the Caribbean have experienced a rapid decline in fertility level during the last decades. The TFR of the region is currently approaching subreplacement levels and several countries such as Brazil, Cuba, Chile, Costa Rica, and Uruguay have already reached a TFR below two children per woman (United Nations 2015). Greater availability and accessibility of contraceptive methods, is considered to be the key factor behind the fertility decline (Guzman et al. 2006). However, teenage fertility rates remain relatively high, with an average age-specific fertility rate (ASFR) of 66\%o (ECLAC 2011; Rodríguez 2014). At the same time, the postponement of first births has proven to be an emergent pattern in the region (Esteve et al. 2012). As a result of several trends, the mean age at birth (MAB) remains close to 27 years, at a similar level to that registered in 1990 (Cabella and Pardo 2014). In many countries, lack of proper and extensive data does not allow researchers to dig deeper into these trends.

Uruguay has particular traits that distinguish it from the rest of the region. It is a small, middle-income country with a population of nearly 3.4 million. It has peculiar characteristics within the developing world, such as a high literacy rate and relatively low income inequality as shown by its Gini coefficient $(0.4)$, which is significantly 
lower than the average for Latin America and the Caribbean (0.5) (ECLAC 2014). The almost complete lack of indigenous people and the high historical level of urbanization also distinguish the country from the rest of Latin American countries: in 2014 the rural population was around 5\% (United Nations 2014).

Its early demographic transition is also atypical of the region. The low level of Uruguayan fertility has been a distinctive feature over the last sixty years (Chackiel 2004; Guzmán et al. 2006). More precisely, Uruguay's long-term fertility decline shows a pattern displaying traits of both European and Latin American countries, though overall more similar to the former (Figure 1). By the mid-20th century, Uruguayan women had less than three children on average, while the average in Latin American was six. By 1970, fertility had remained stable for a long time (TFR $=2.8-3.0$ children per woman); it then decreased to 2.5 in the mid-1980s. No significant changes took place for the next ten years. Between 1996 and 2011 the TFR in Uruguay experienced a remarkable decline, reaching 1.9 children per woman (INE 2014).

Uruguay has been experiencing significant family change over the last thirty years, which has become particularly marked since the beginning of the 1990s. The marriage rate halved between the end of the 1980s and the first decade of the 2000s; consensual unions increased in an unprecedented manner (four in five couples under the age of 30 choose this form of partnership, as compared to 1 in 10 in 1984); out-of-wedlock births grew from one fifth of the total to $70 \%$ over the same period; and divorces and separations became more frequent (Cabella 2009). These are some of the reasons why the Uruguayan population seems to be moving towards the so-called 'Second Demographic Transition' (SDT), even though some of the most important SDT indicators are only observed in the upper and middle strata (Cabella 2009; Ciganda 2008; Fernandez, Fostik, and Varela 2012). The recent decline of the TFR in Uruguay can be described as an extensive process, affecting women from all social backgrounds (Varela et al. 2014), which is accompanied by an increasing heterogeneity in the timing of fertility and union formation. 
Figure 1: Period TFR in Uruguay and selected regions and countries, 1950-2015

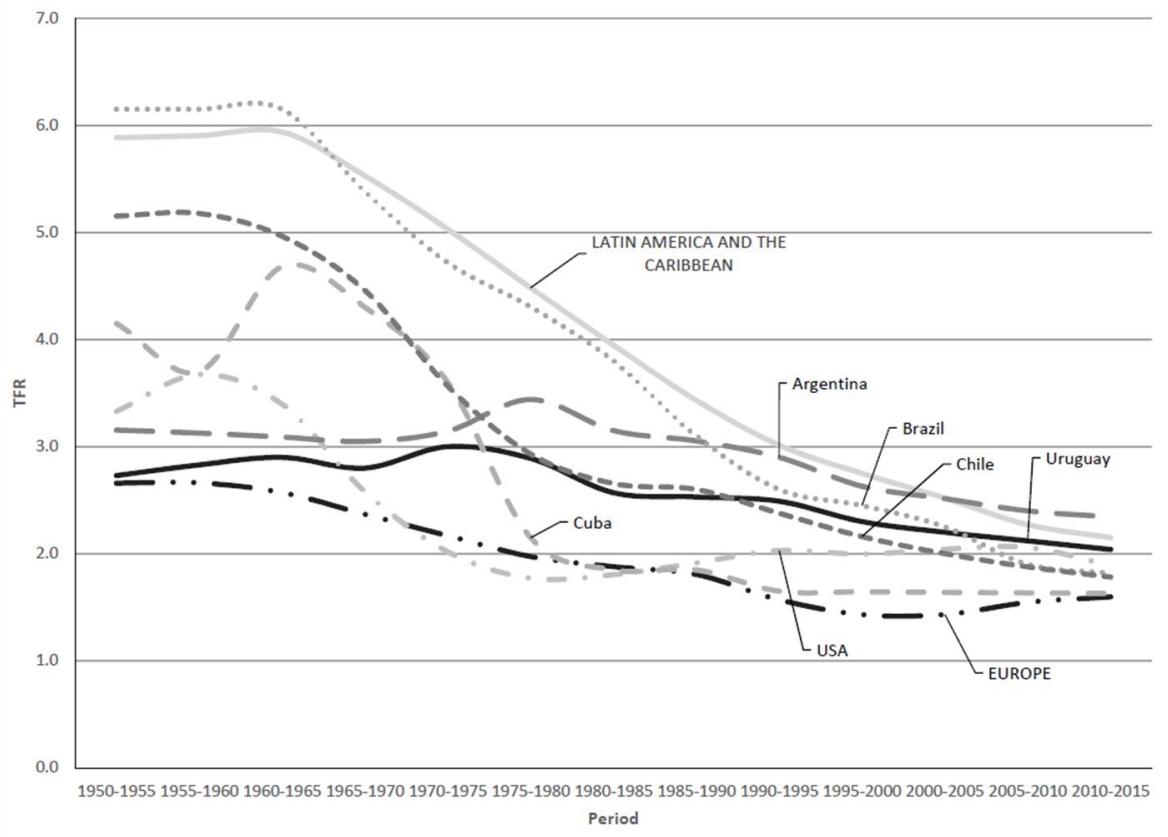

Source: United Nations, World Population Prospects: The 2015 Revision.

While younger cohorts of women with less formal education and from disadvantaged backgrounds did not experience any postponement in their age at first birth, those with more education have been increasingly delaying their entry into motherhood (Fostik 2014; Fernandez, Fostik, and Varela 2012; Nathan 2013; Videgain 2006). A recent study that compared the median age at first birth of women born in 1955 with those born in 1975 showed that the gap between lower and higher educational attainment groups increased from less than 6 to almost 12 years (Nathan 2015). The persistence of high rates of teenage fertility is a critical part of the explanation. Even though these rates have decreased over the last two decades they are still as high as the rates of the 1960s and 1970s, when the TFR in Uruguay was nearly three children per woman (Varela, Fostik, and Pollero 2008). This pattern of a much slower decline in teenage fertility rates than in total fertility has also been found in several other Latin America countries (Rodriguez and Cavenaghi 2013). 
This marked difference in reproductive behavior is linked to a set of social changes in Uruguayan society. Perhaps the most important is the process of social fragmentation triggered by the crisis of a welfare regime that promoted social integration through the state (Rama 1987). The deterioration of this "hyperintegrated" society, an increasingly segmented labor market, and the growing inability to retain disadvantaged young people in school, has led to differentiated trajectories of youth upon reaching adult life (Cardozo and Iervolino 2009; Ciganda 2008; Filardo 2015; Videgain 2006).

\section{Data and measures}

Annual series of births by age of mother and birth order between 1996 and 2011 were compiled using microdata provided by the Ministry of Public Health and the National Institute of Statistics of Uruguay. We worked with births records from the Live Birth Certificate System between 1996 and 2007. Due to the increasing proportion of births registered without information on mother's parity in 2008-2011, we linked the records of all the children born in those years to the Perinatal Information System database. ${ }^{4}$

Female population exposures between 1996 and 2011 - denominators for age and birth-order-specific fertility rates - were computed using official mid-year population estimates by age and sex, provided by the National Statistics Institute of Uruguay, 2013 Revision. The relative age and parity distribution of women was first estimated for the starting year (1996) using population census data, and extrapolated for every subsequent year (1997-2011) by using the reconstructed age- and order-specific fertility rates. Our calculations were based on those documented in the Methods Protocol for the Human Fertility Database (Jasilioniene et al. 2012). To check the accuracy of this procedure we compared the proportion of women by age and parity in 2011 as a result of the extrapolation method with data from the 2011 population census. ${ }^{5}$ As shown in Figure A-1, the extrapolation method provides a relative distribution of women by age and parity that is consistent with data from the 2011 census. The largest differences were observed between the ages of 20 and 25, mostly in proportion to the number of women with parity 0 , which should not significantly affect our results.

\footnotetext{
${ }^{4}$ A subsequent step to compute birth order information was to retrieve birth history data of the mother for a given number of cases where the mother had had two or more children between 2003 and 2011 (based on previous or subsequent birth records and information about the number of previous pregnancies). Finally, data was tabulated by year of occurrence for ages 14 to $50+$ and birth orders 1 to $4+$, and weighted using the under-coverage values published by the National Institute of Statistics (see INE 2014).

${ }^{5}$ In the Annex, we provide a graphical assessment of this procedure, based on a figure used by Castro and Zeman (2014). Census data was adjusted to report the results for January $1^{\text {st }}, 2011$.
} 
Unconditional and conditional age- and birth-order-specific fertility rates between 1996 and 2011 were estimated. The conditional fertility rates by age and birth order $m_{i}(x, t)$ were computed from the number of annual births from women of age $x$ and order $i$ in year $t$ divided by the number of women of age $x$ and parity $i-1$ estimated for midyear $t$. The following summary indicators were then computed, using period fertility tables, for each order and for all orders combined:

- Parity- and age-adjusted total fertility rate $\left(\mathrm{PATFR}_{\mathrm{i}}\right)$, a summary measure that can be described as the total fertility rate derived from conditional rates that control for changes in the age and parity composition of women.

- Table mean age at birth $\left(\mathrm{TMAB}_{\mathrm{i}}\right)$, the version of the mean age at birth that relies on the age distribution of the fertility table number of births.

We compare PATFR and TMAB with conventional summary measures TFR and $\mathrm{MAB}$, also computed for the period. The former are parity-adjusted indicators and therefore provide information of the quantum and tempo of fertility without compositional distortions. However, they do not control for tempo distortions (Bongaarts and Sobotka 2012; Kohler and Ortega 2002).

In fact, both TFR and PATFR, and its components by birth order, are affected by annual changes in the mean age at birth. Thus, we introduce another measure, TFRp*, to describe potential tempo distortions in the results section. TFRp* uses fertility rates of the first kind with births of each order treated as separate non-repeatable events, ${ }^{6}$ adjusting also for distortions that come from the changing parity distribution of women of reproductive age. It does not include all women aged $x$, as in the cases of TFR, but women aged $x$ who have a parity $j$, given $j<i$ (Bongaarts and Sobotka 2012). The PATFR (Parity-Age Total Fertility Rate), an indicator developed by Rallu and Toulemon (1994), as well as the adjusted version, PATFR*, provided by Kohler and Ortega (2002), include denominators where the exposed population for each age $x$ is composed by women of age $x$ and parity $i-1$. The adjustment variant needs a more complex computation, involving the change in the mean age at birth and also its variance. Bongaarts and Sobotka (2012) demonstrated that this adjusted version performs poorly as compared to TFRp*, in terms of its usefulness as a proxy of the cohort-completed fertility rate (especially for higher orders) ${ }^{7}$. This is the reason why we choose TFRp* to measure period fertility controlling for both tempo and parity effects.

\footnotetext{
6 "Any recurrent event may be resolved into a series of non-recurrent events, which can be analyzed separately" Bongaarts and Feeney (2006: 2).

${ }^{7}$ This can be explained by the computing of TFRp*, which involves independent calculations for each birth order, while in PATFR* those calculations are linked through the use of a fertility table.
} 
At the same time, Bongaarts and Feeney (2006) proved that TMAB1 and MAB1 can show different levels, as tempo distortions produce an upward bias in the TMAB1 (derived from conditional fertility rates) when the MAB1 of a specific birth order is increasing. We analyze if this is the case for Uruguayan TMAB1 and MAB1, and subsequent birth orders. For comparative purposes, the conventional mean age at first birth (MAB1) was used. It is available for several countries and across a long span of years in the Human Fertility Database/Collection. The standard deviation in the mean age at first birth (sdMAB1) was also used, in this case to examine the level of fertility dispersion by age in Uruguay and other countries.

\section{Results}

\subsection{Trends in quantum and tempo of fertility by birth order}

Figure 2 presents the evolution of the three summary measures of period fertility quantum, TFR, PATFR, and TFRp*, between 1996 and 2011. TFR and PATFR show a very similar evolution: total fertility decreased from 2.5 to 1.9 children per woman. TRFp* departs from TFR and PATFR in several years, showing that tempo effects played a role during certain periods in the decline of the TFR in Uruguay ${ }^{8}$. Between 2002 and 2004, both TFR and PATFR may be deflated due to a short period of postponement of fertility, likely to have been fueled by the extensive economic crisis suffered by the country in those years. Mild tempo effects are also displayed from 2007 to 2010, where TFRp* values remained above TFR and PATFR. In the absence of composition and tempo effects the decline of the total fertility in Uruguay would have been less intense, reaching an average of 2.0 children per woman in 2010 instead of the 1.9 observed with the TFR.

\footnotetext{
${ }^{8}$ In the case of Uruguay, the performance of the TFRp* does not show its usual stability. However, its performance is similar to that of countries such as Bulgaria and Estonia, which during the 1990s underwent significant changes in the timing of childbearing within only a few years (Bongaarts and Sobotka 2012).
} 


\section{Figure 2: $\quad$ TFR, PATFR, and TFRp*, Uruguay 1996-2011}

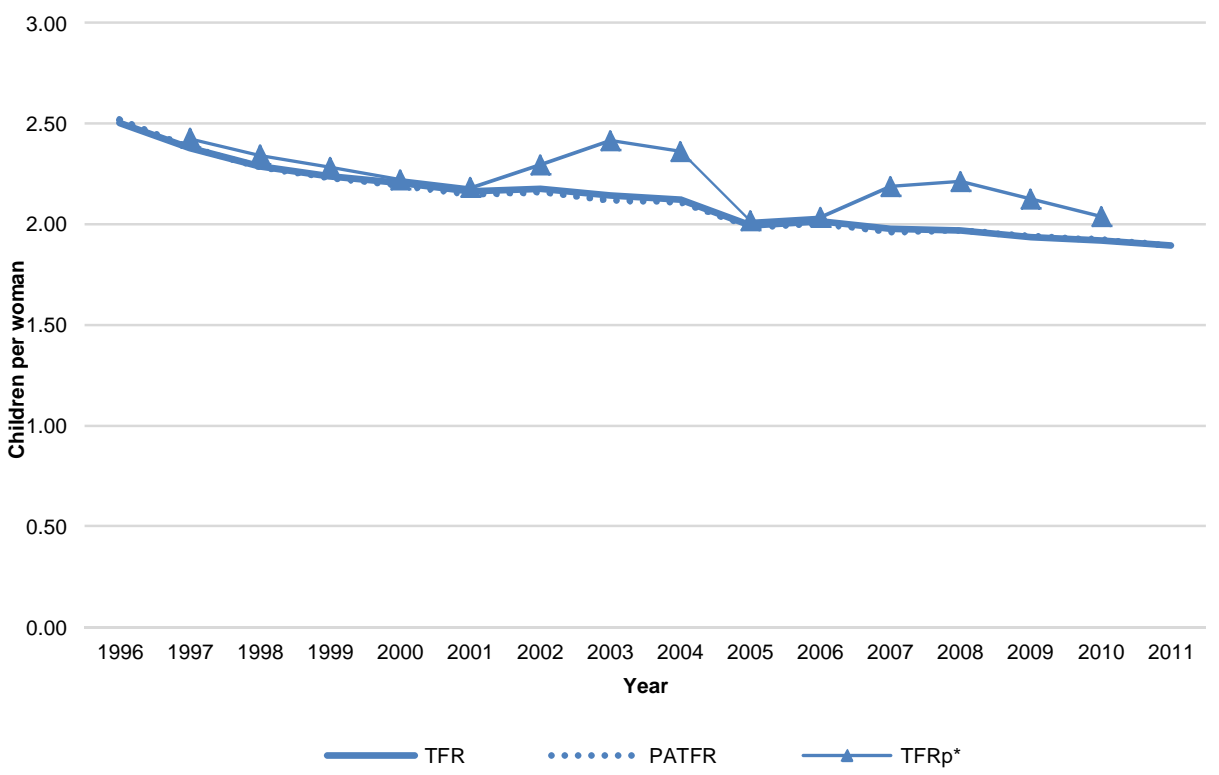

Source: Authors' calculations based on Live-Birth Certificate and Perinatal Information System (Ministry of Public Health-Office of National Statistics of Uruguay), age-parity weights from 1996 national census and mid-year population estimates (Office of National Statistics of Uruguay 2013 revision).

As shown in Figure 3, TFR and PATFR exhibit different trends in birth-orderspecific fertility, in spite of showing similar levels when all birth orders are considered combined. For instance, the average number of births per woman in PATFR1 and PATFR2 is higher than in TFR1 and TFR2 in the period considered, but PATFR4+ is lower than TFR4+. Both composition and tempo effects account for lower values of TFR1 and TFR2, as seen with the evolution of TFRp* for $1^{\text {st }}$ and $2^{\text {nd }}$ birth orders. There is little difference between the evolution of PATFR and TFRp* for first births, and both present almost no changes in their levels. Similar trends are also displayed by PATFR2 and TFRp*2, although the latter presents two bulges, in 2002 and 2003, and 2008-2010. Likewise, TFRp*3 and TFRp*4+ show specific peaks in those years, especially in 2004. 
Figure 3: TFR, PATFR, and TFRp* by birth order, Uruguay 1996-2011

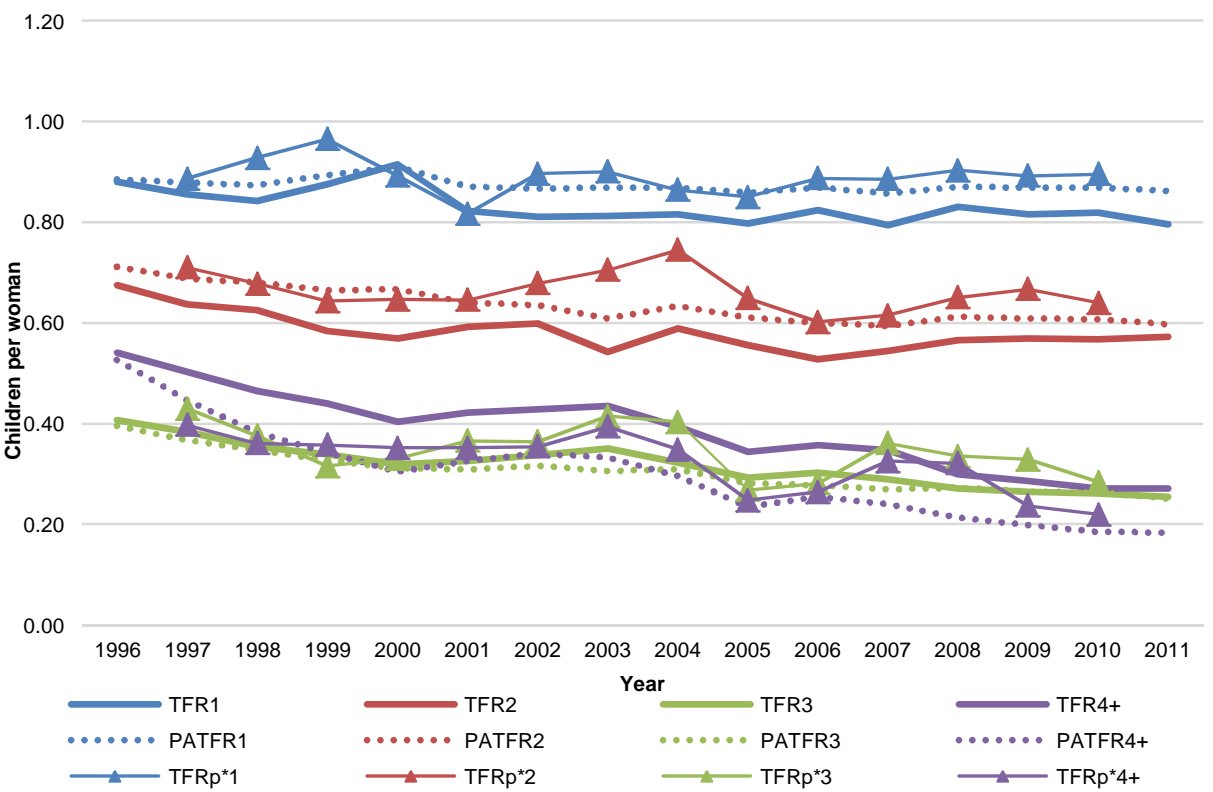

Source: Authors' calculations based on Live-Birth Certificate and Perinatal Information System (Ministry of Public Health-Office of National Statistics of Uruguay), age-parity weights from 1996 national census and mid-year population estimates (Office of National Statistics of Uruguay 2013 revision).

Figure 4 shows that women in Uruguay are delaying childbearing. MAB increased in birth orders 1 to 3, especially in the last years. These changes, however, occurred at a slow pace, particularly for first births. Between 1996 and 2011, MAB1 increased just one year (23.7 to 24.7) and remained lower than that observed in countries with low fertility (see Figure 6 ).

Bongaarts and Feeney (2006) pointed out that TMAB1 values tend to be higher than MAB1 when MAB1 is increasing due to tempo distortions. Our results show that this inflating effect can also be observed - and tends to be more intense - in subsequent birth orders. 


\section{Figure 4: $\quad$ Mean age at birth (MAB) and table mean age at birth (TMAB) by birth order, Uruguay 1996-2011}

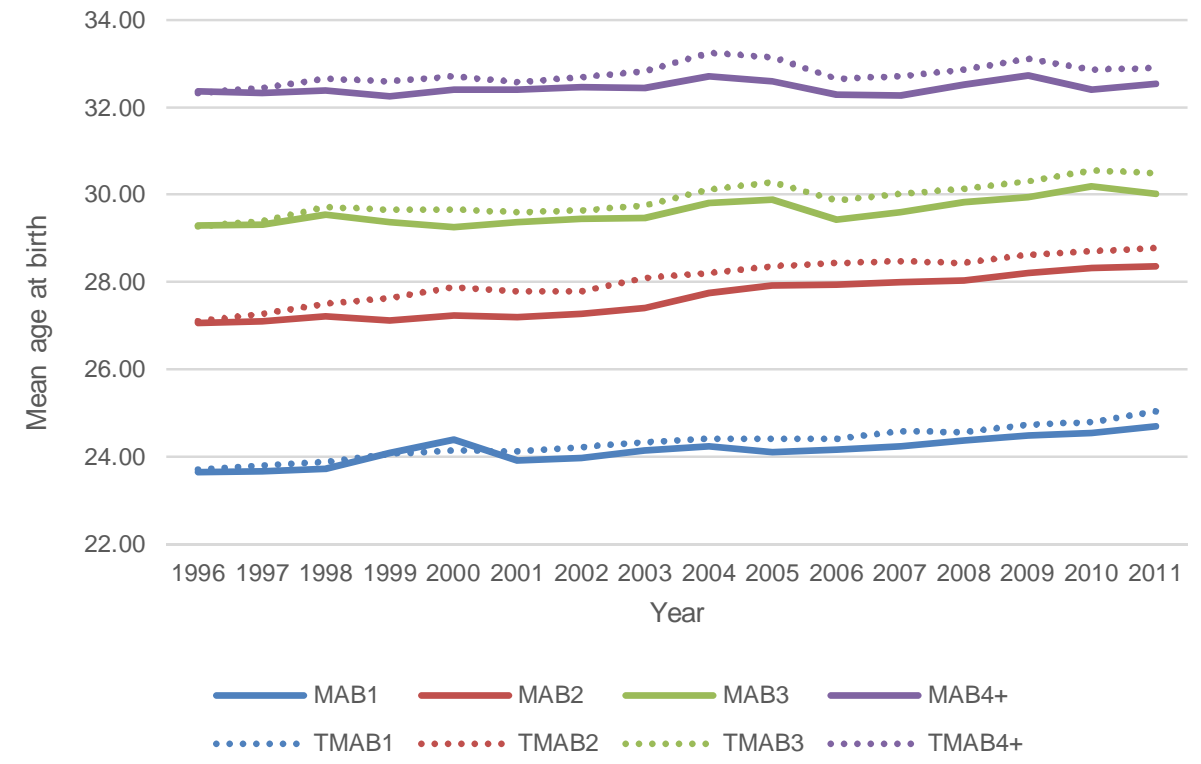

Source: Authors' calculations based on Live-Birth Certificate and Perinatal Information System (Ministry of Public Health-Office of National Statistics of Uruguay), age-parity weights from 1996 national census and mid-year population estimates (Office of National Statistics of Uruguay 2013 revision).

All things considered, it is clear that fertility decline in Uruguay between 1996 and 2011 was largely driven by the lower fertility rates of order 3 and 4+ (Table 1). In fact, the decrease in fertility of those birth orders accounts for as much as $70 \%$ (TFR) or $80 \%$ (PATFR and TFRp*) of the total fertility decrease. The contribution of birth order 2 was smaller, close to $18 \%$. As shown in Table 1 , when controlled by parity composition and tempo effects, fertility decline in first births is negligible. In other words, fertility decline was linked to a parity-specific stopping model with a moderate 'deflating' effect as a result of changes in the composition of female exposure and age at first and second births. 
Table 1: TFR, PATFR, and TFRp* by birth order, absolute change, and relative contribution to total fertility decline, Uruguay 1996 and 2011

\begin{tabular}{llccccr}
\hline & & \multicolumn{4}{c}{ Birth order } & \\
\cline { 3 - 6 } & & $\mathbf{1}$ & $\mathbf{2}$ & $\mathbf{3}$ & $\mathbf{4 +}$ & Total \\
\hline \multirow{3}{*}{ TFR } & 0.88 & 0.68 & 0.41 & 0.54 & 2.51 \\
& 2011 & 0.80 & 0.57 & 0.26 & 0.27 & 1.90 \\
& Absolute change & -0.09 & -0.10 & -0.15 & -0.27 & -0.61 \\
& Relative contrib. & $\mathbf{1 4 \%}$ & $\mathbf{1 7 \%}$ & $\mathbf{2 5 \%}$ & $\mathbf{4 4 \%}$ & $\mathbf{1 0 0 \%}$ \\
\hline \multirow{3}{*}{ PATFR } & 0.89 & 0.71 & 0.40 & 0.53 & 2.52 \\
& 2011 & 0.86 & 0.60 & 0.25 & 0.18 & 1.90 \\
& Absolute change & -0.02 & -0.11 & -0.14 & -0.34 & -0.62 \\
& Relative contrib. & $\mathbf{4 \%}$ & $\mathbf{1 8 \%}$ & $\mathbf{2 3} \%$ & $\mathbf{5 5 \%}$ & $\mathbf{1 0 0 \%}$ \\
\hline \multirow{4}{*}{ TFRp* } & 1996 & 0.89 & 0.71 & 0.43 & 0.40 & 2.43 \\
& 2010 & 0.90 & 0.64 & 0.28 & 0.22 & 2.04 \\
& Absolute change & 0.01 & -0.07 & -0.15 & -0.18 & -0.39 \\
& Relative contrib. & $\mathbf{- 2 \%}$ & $\mathbf{1 8 \%}$ & $\mathbf{3 8 \%}$ & $\mathbf{4 6 \%}$ & $\mathbf{1 0 0 \%}$ \\
\hline
\end{tabular}

Source: Authors' calculations based on Live-Birth Certificate and Perinatal Information System (Ministry of Public Health-Office of National Statistics of Uruguay), age-parity weights from 1996 national census and mid-year population estimates (Office of National Statistics of Uruguay 2013 revision).

\subsection{Conditional ASFR by birth order in Uruguay}

Conditional age-specific fertility rates provide a more complete account of the evolution of fertility. Firstly, if we consider all birth orders combined, these rates show that fertility levels have decreased in all years and for almost all reproductive ages (Figure 2a). Nevertheless, the shape of the age schedule remains almost unchanged, with a plateau that extends from ages 22 to 34 . This unusual picture becomes more accentuated over time. In a context of fertility decline of orders 3 and 4+, we would not expect this extended plateau to be an expression of uniform fertility rates across the entire age range. Instead, it may show an aggregate effect of different trends by birth order and age, which balance each other out. Therefore we plotted conditional ASFR by birth order to get a more complete impression of order-specific trends.

Changes in conditional age-specific fertility rates for first births (Figure 5b) encompassed the consolidation of an asymmetric bimodal shape across the period, in which the first peak remains stable at age 20 and the second increases from ages 29 to 32. Conditional ASFR for second births depicts a more tapered bimodal curve (Figure 
5c), which disappears when plotting ASFR for third births (Figure 5d). This increasing heterogeneity of reproductive behavior is driven by two different trends: firstly, the persistence of high teenage fertility rates, and secondly, a growing number of women delaying their entry into motherhood.

Results for conditional age-specific fertility rates for first births $(m l(x))$ are consistent with previous research in Uruguay from a cohort approach that showed the social status polarization in the age at first childbirth (Nathan 2015 and 2013; Videgain 2006).

\section{Figure 5a-5d: Age-specific fertility rates (all birth orders combined) and conditional age-specific fertility rates for first, second, and third birth orders (three-age moving average), Uruguay 1996, 2001, 2006, and 2011}

All birth orders combined

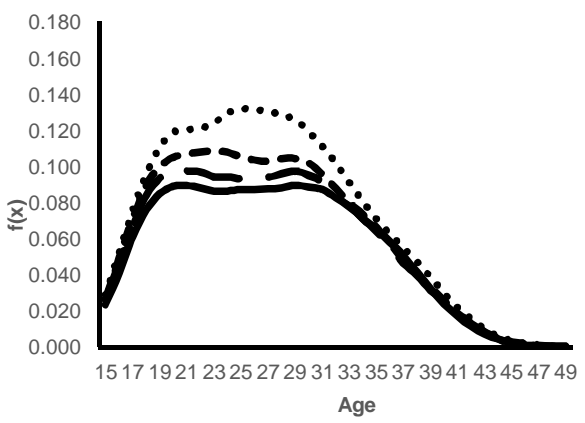

Birth order 2

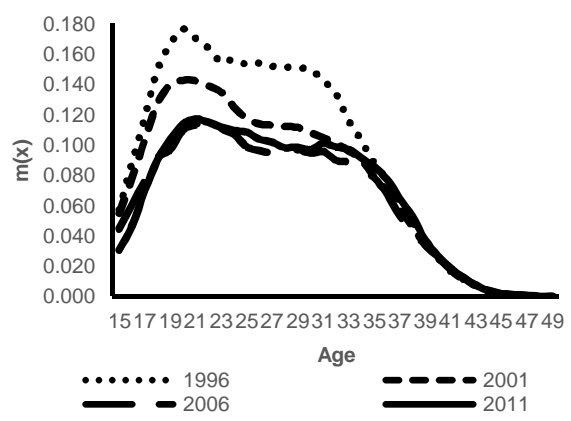

Birth order 1

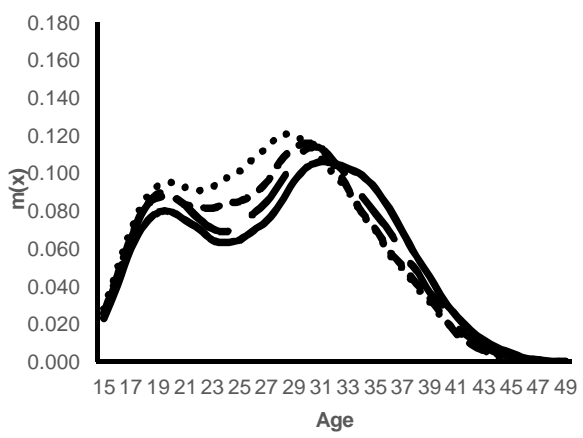

Birth order 3

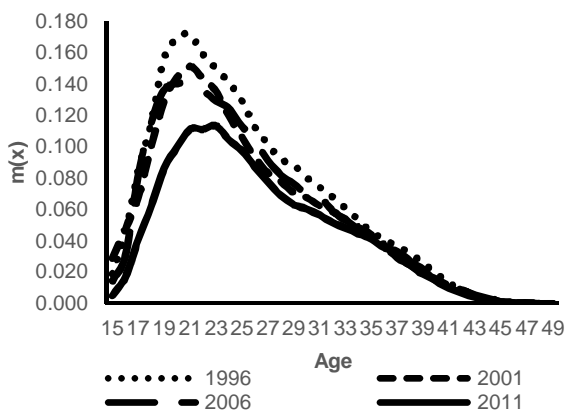

Source: Authors' calculations based on Live-Birth Certificate and Perinatal Information System (Ministry of Public Health-Office of National Statistics of Uruguay), age-parity weights from 1996 national census, and mid-year population estimates (Office of National Statistics of Uruguay 2013 revision). 


\subsection{MAB1 and sdMAB1 in Uruguay and selected countries}

Looking for patterns in the shape of the ASFR distribution is certainly helpful to achieve a thorough description of fertility trends, but it is also necessary to use standardized measures to depict the extent to which the Uruguayan fertility schedule differs from that of other countries. In order to do so, we compared the MAB1 and its standard deviation for Uruguay with those of selected countries of Latin America and the Caribbean, Europe, and North America (Chile, Denmark, Hungary, Italy, Portugal, Serbia, Spain, Sweden, and USA). Besides using the MAB1 to compare the extent of the postponement of first births, we use its standard deviation to analyze dispersion, which could be important, considering the bimodal pattern commented on in the previous section.

The lowest MAB1 available in each country was selected to depict the evolution over the following 15 years, the same time-span considered in the analysis of the Uruguayan data (1996-2011). Table 2 shows the year of the initial data point in each country. In general, the selected countries also show a similar TFR at the beginning of the period (not shown). ${ }^{9}$ Nowadays, those countries tend to have much higher MAB1 values. For instance, the OECD average is currently 28 years $^{10}$.

The lowest value of the MAB1 in the years of available data for each country extends from ages 22.2 (USA in 1963) to 24.8 (Spain in 1979). Uruguay has an intermediary value of 23.7 years (1996) (Table 2). More recent initial values tend to be higher, especially in European countries, where the delay in first births began sooner than other regions. The increase in the MAB1 of Uruguay is comparatively low, both in terms of absolute increase and proportional change (Table 3 and Figure 6).

\footnotetext{
${ }^{9}$ Every country shows a TFR between 1.8 and 2.5, except for the USA, which has higher values.

10 OECD Family Database: Age of mothers at childbirth. http://www.oecd.org/els/soc/SF_2_3_Age_ mothers_childbirth.pdf.
} 
Table 2: $\quad$ Year of lowest MAB1 in available period (Uruguay and selected countries)

\begin{tabular}{lcc}
\hline Country & MAB1 & Year \\
\hline USA & 22.24 & 1963 \\
Hungary & 22.41 & 1976 \\
Serbia & 22.54 & 1971 \\
Chile & 23.22 & 1995 \\
Denmark & 23.48 & 1968 \\
Uruguay & 23.66 & 1996 \\
Portugal & 23.90 & 1983 \\
Sweden & 24.22 & 1974 \\
Italy & 24.65 & 1975 \\
Spain & 24.81 & 1979 \\
\hline
\end{tabular}

Source: Authors' calculations based on data from the Human Fertility Database/Collection.

Table 3: Change in MAB1 in the fifteen years following the lowest available value (\%) (Uruguay and selected countries)

\begin{tabular}{lc}
\hline Country & \% change \\
\hline Spain & 13.30 \\
Portugal & 9.37 \\
Italy & 9.21 \\
Sweden & 8.63 \\
Denmark & 7.58 \\
Serbia & 4.61 \\
USA & 4.59 \\
Chile & 4.57 \\
Uruguay & 4.40 \\
Hungary & 3.48 \\
\hline
\end{tabular}

Source: Authors' calculations based on data from the Human Fertility Database/Collection. 
Figure 6: MAB1 in Uruguay and selected countries (fifteen-year period following the lowest available MAB1 value)

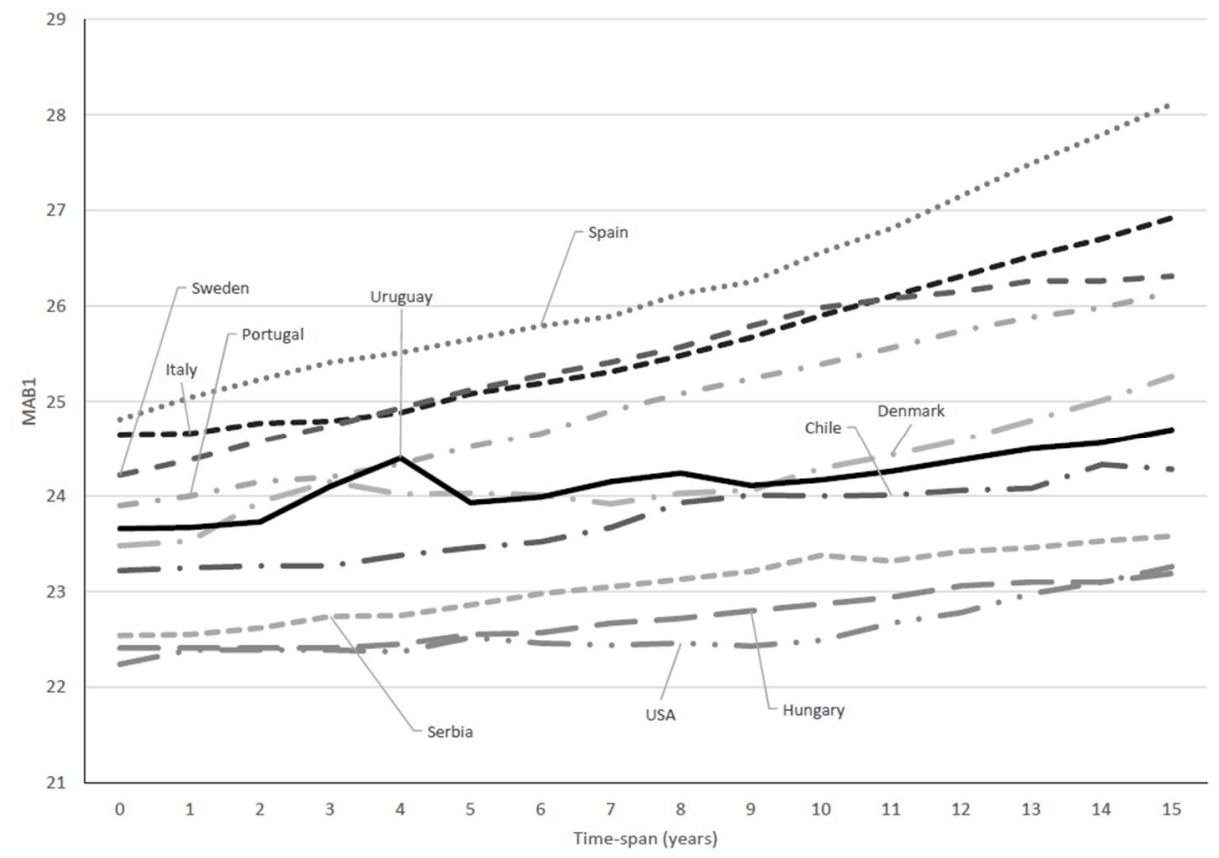

Source: Authors' calculations based on data from the Human Fertility Database and the Human Fertility Collection.

More impressively, Uruguay stands out as the country with the highest standard deviation of all those selected. It is followed by Chile, despite Chile having also started with the highest values (and so a priori having less room to increase) (Figure 7). The USA does not show a particularly high standard deviation during this period, which may be explained by the fact that the data only starts in the 1960s: the pattern of increasing heterogeneity showed by Sullivan (2005) started in the 1990s. 
Figure 7: $\quad$ Standard deviation of MAB1 in Uruguay and selected countries (15-year period following the lowest available sdMAB1 value)

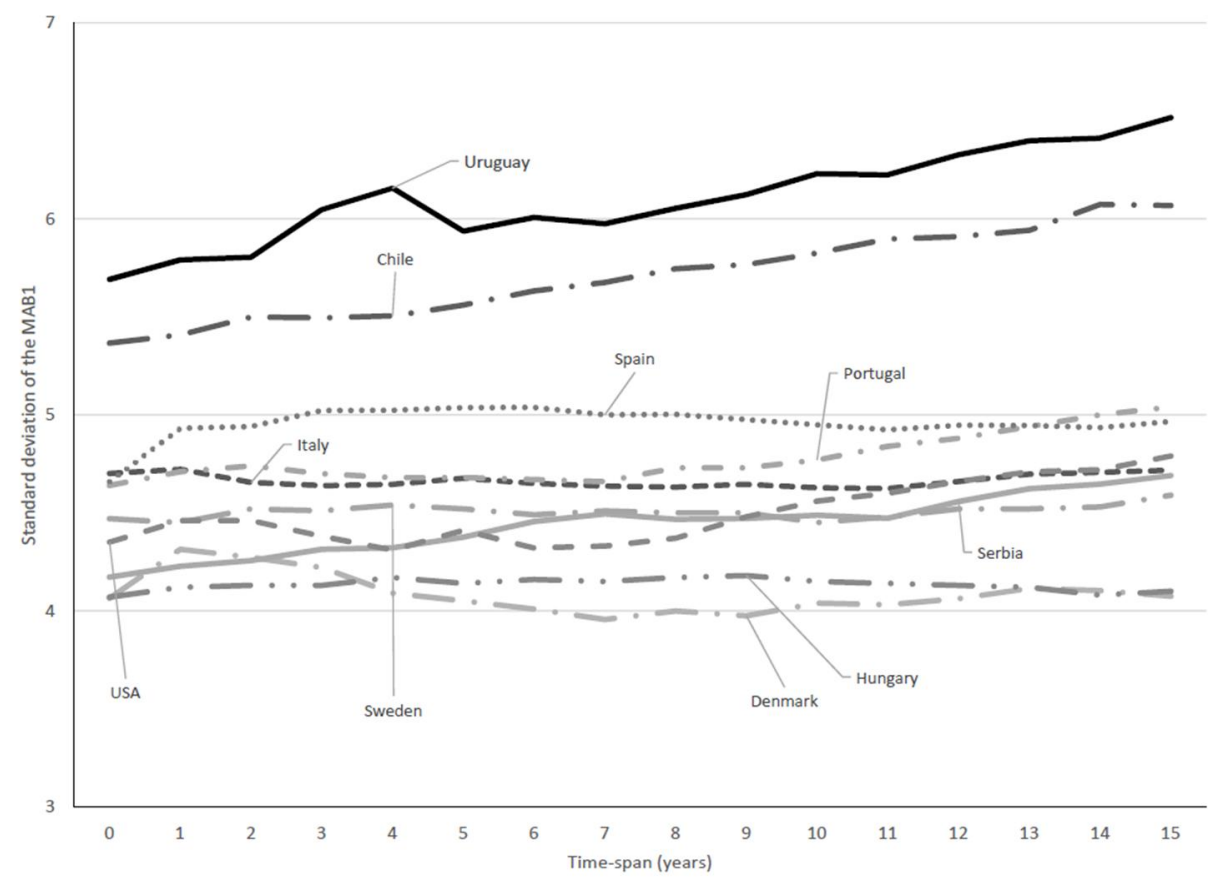

Source: Authors' calculations based on data from the Human Fertility Database and the Human Fertility Collection.

\section{Conclusions}

The aim of this study was to analyze the changes in the level and timing of fertility in Uruguay between 1996 and 2011 using mostly summary measures by birth order and conditional ASFR. We presented new evidence for a better description of the patterns of fertility decline in Uruguay, looking for trends in childlessness, family limitation, and postponement of childbearing from a period approach. To the best of our knowledge, this is the first paper to analyze the trends in fertility by birth order for a Latin American country using vital statistics.

The data suggests that the decline in TFR between 1996 (2.5) and 2011 (1.9) in Uruguay was mainly a consequence of the reduction in the number of higher order births and a moderate postponement of first and second births. The proportion of childless women remained virtually unchanged, and thus its contribution to the decline 
of the total fertility was almost nil. Among the possible drivers of fertility decline, parity-specific fertility control seems to have been the most important.

An increase in the period mean age at first and second births was also shown, which might reflect the onset of fertility postponement in Uruguay. Although Uruguay seems to be at the forefront of the group of countries that have already started the postponement phase of the Second Demographic Transition (Esteve et al. 2012), the pace of childbearing postponement in 1996-2011 has been relatively slow if compared to the annual change of mean age at first birth for European countries during the "postponement transition" (Kohler, Billari, and Ortega 2002; Goldstein, Sobotka, and Jasilioniene 2009). However, the increase of the mean age at birth for lower birth orders was sufficient to produce the deflation of the conventional TFR for specific years between 1996 and 2011.

One of the main findings of this study is that conditional age-specific first-birth fertility rates exhibit an asymmetric bimodal distribution with peaks around ages 20 and 30 , which can be observed to a lesser extent in second-order births. The emergence and consolidation of this pattern accompanies an increasing heterogeneity in the timing of childbearing, which is larger than that of other countries selected for comparison (USA, some European countries, Chile), as can be observed when using the standard deviation in the mean age at first birth.

In fact, high and increasing heterogeneity in reproductive behavior in the context of decreasing fertility levels might be a distinctive feature of Uruguay. All the evidence suggests that women from lower social strata have not significantly changed their behavior regarding their age at first childbirth, while women of middle to high social strata have experienced some postponement (Videgain 2006; Nathan 2015, 2013; Fernández Soto, Fostik, and Varela 2012; Varela, Fostik, and Pollero 2008; Cabella 2009). The coexistence of both patterns produces a moderate increase in the MAB1 and the accentuation of the bimodal curves of fertility rates by age at first birth.

In this regard, postponement transition in Uruguay cannot be approached without considering the consolidation of the social status polarization of fertility timing. It is reasonable to assume that the forces that lead Uruguayan women to delay motherhood act on a particular population group, which seems to be changing its birth timing as a function of educational and labor-market opportunities. On the other hand, an important segment of the population appears to be immune to these changes. It is to be expected that this current model of dual reproductive behavior, inasmuch as it is linked to structural social inequalities, will remain unchanged in the coming years. Care should therefore be taken not to interpret the onset of fertility postponement as a universal change in the Uruguayan population, as in the case of other spread-out behaviors (e.g., cohabitation - Cabella 2009). 
A plausible scenario for the years to come is that while Uruguay consolidates its low fertility regime and eventually goes through the postponement transition, the entire population will converge into a more homogenous quantum behavior (with TFR levels below two children per woman ${ }^{11}$ ) but remain divergent in fertility timing based on social strata. In other words, the gap in reproductive behavior resulting from the differential educational and working opportunities mentioned above will be focused on timing and not quantum.

Although the lack of information on other Latin American countries does not allow us to infer the existence of a regional pattern, the similarity in the trajectories of Chile and Uruguay in recent years (Lima et al. 2015) stands out from the rest of the countries considered. The increase in the heterogeneity of timing of first births and its relation to social inequality patterns are both going to form part of the regional research agenda in the forthcoming years.

\section{Acknowledgements}

This paper was produced with funding from the Comisión Sectorial de Investigación Científica (CSIC, Universidad de la República, Uruguay) under the research project "El descenso de la fecundidad en Uruguay (1996-2011): ¿cuál es su verdadera dimensión?". We would like to thank the Ministry of Public Health and the National Institute of Statistics of Uruguay for allowing us to access the data and for their technical support. We are also very thankful to the anonymous reviewers of an earlier version of this paper for their valuable recommendations and to Kristof Zeman for his useful comments about our computations of female population exposures.

\section{Corrections}

The previous version included wrong TFRp* values introduced by an incorrect formula of $r$ (that accounts for the inter-annual variation of MAB) in the STATA code. Instead of $r(t)=[M A B(t+1)-M A B(t-1)] / 2$, we had left this formula as $[\mathrm{MAB}(\mathrm{t}+1)-\mathrm{MAB}(\mathrm{t})] / 2$.

Small differences arise in our results with corrected TFRp* and they do not affect the core of our analysis. However, Figures 2 and 3, and Table 1, were TFRp* results are shown, had to be adjusted with new calculations. Some TFRp* values mentioned in the text on pages 570, 571, and 573 also needed to be revised.

\footnotetext{
${ }^{11}$ The modal desired fertility in the country (Peri and Pardo 2008).
} 


\section{References}

Batyra, E. (2015). Fertility and changing pattern of childbearing timing in Colombia. Paper presented at the Population Association of America, 2015 Annual Meeting, San Diego, CA.

Bongaarts, J. and Feeney, G. (2006). The Quantum and Tempo of Life-Cycle Events. Vienna Yearbook of Population Research 4: 115-151.

Bongaarts, J. and Sobotka, T. (2012). A Demographic Explanation for the Recent Rise in European Fertility. Population and Development Review 38(1): 83-120. doi:10.1111/j.1728-4457.2012.00473.x.

Cabella, W. (2009). Dos décadas de transformaciones de la nupcialidad uruguaya. La convergencia hacia la segunda transición demográfica. Estudios Demográficos y Urbanos 24(2): 389-427.

Cabella, W. and Pardo, I. (2014). Hacia un régimen de baja fecundidad en América Latina y el Caribe, 1990-2015. In: Cavenaghi, S. and Cabella, W. (eds.). Comportamiento reproductivo y fecundidad en América Latina: una agenda inconclusa. Rio de Janeiro: ALAP: 13-31.

Cardozo, S. and Iervolino, A. (2009). Adiós juventud: tendencias en las transiciones a la vida adulta en Uruguay. Revista de Ciencias Sociales 22(25): 60-81.

Castro, R. and Zeman, K. (2014). Human Fertility Database documentation: Chile [electronic resource]. www.humanfertility.org.

Chackiel, J. (2004). La transición de la fecundidad en América Latina 1950-2000. Papeles de Población 10(41): 9-58.

Ciganda, D. (2008). Jóvenes en transición hacia la vida adulta: el orden de los factores ¿no altera el resultado? In: Varela, C. (ed.). Demografía de una sociedad en transición: la población uruguaya a inicios del siglo XX. Montevideo: Trilce.

ECLAC (Economic Commission for Latin America and the Caribbean) (2011). Social Panorama of Latin America 2011. Santiago: United Nations.

ECLAC (Economic Commission for Latin America and the Caribbean) (2014). Social Panorama of Latin America 2014. Santiago: United Nations.

Esteve, A., Garcia-Roman, J., Lesthaeghe, R., and Lopez-Gay, A. (2012). The "Second Demographic Transition" Features in Latin America: the 2010 Update [unpublished manuscript]. Barcelona: Centre d'Estudis Demogràfics. 
Fernández Soto, M., Fostik, A., and Varela, C. (2012). Convergencia y divergencia en el pasaje a la vida adulta: la transición a la maternidad. Paper presented at the $\mathrm{V}$ Congreso de la Asociación Latinoamericana de Población, Montevideo, Uruguay.

Filardo, V. (2015). Cambios y permanencias en las transiciones a la vida adulta de los jóvenes en Uruguay (2008-2013). Cuadernos Temáticos de la ENAJ nº1, MIDES-INJU-FCS Udelar.

Fostik, A.L. (2014). La naissance du premier enfant et la transition à la vie adulte en Uruguay [Ph.D. Thèse, Doctorat en démographie]. Université du Québec.

Goldstein, J.R., Sobotka, T., and Jasilioniene, A. (2009). The end of 'lowest-low' fertility? Population and Development Review 35(4): 663-699. doi:10.1111/ j.1728-4457.2009.00304.x.

Guzmán, J.M., Rodríguez, J., Martínez, J., Contreras, J.M., and González, D. (2006). The Demography of Latin America and the Caribbean since 1950. Population-E 61(5-6): 519-576. doi:10.3917/pope.605.0519.

INE (National Statistics Institute of Uruguay) (2014). Estimaciones y proyecciones de la población de Uruguay: metodología y resultados, Revisión 2013. Montevideo: Instituto Nacional de Estadística.

Jasilioniene, A., Jdanov, D., Sobotka, T., Andreev, E.M., Zeman, K., and Shkolnikov, V.M. (2012). Methods Protocol for the Human Fertility Database. 10.08.2012 version [electronic resource]. www.humanfertility.org.

Kohler, H.P. and Ortega, J.A. (2002). Measuring Low Fertility: Rethinking Demographic Methods. MPIDR Working Paper, WP 2002-001. Max Planck Institute for Demographic Research.

Kohler, H.P., Billari, F.C., and Ortega, J.A. (2002). The emergence of lowest-low fertility in Europe during the 1990s. Population Development Review 28(4): 641-680. doi:10.1111/j.1728-4457.2002.00641.x.

Lima, E., Zeman, K., Castro, R., Nathan, M., and Sobotka, T. (2015). Bimodal AgeSpecific Fertility Profiles in Latin America: The Case of Chile and Uruguay. Paper presented at the Population Association of America, 2015 Annual Meeting, San Diego, CA. 
Miranda-Ribeiro, A., Rios-Neto, E., and Ortega, J.A. (2008). Declínio da fecundidade no Brasil e México e o nível de reposição: efeitos tempo, parturição e quantum. In: Wong, L. (ed.). Población y Salud Sexual y Reproductiva en América Latina. Rio de Janeiro: ALAP: 81-100.

Nathan, M. (2015). La creciente heterogeneidad en la edad al primer hijo en Uruguay: un análisis de las cohortes 1951-1990. Notas de Población 100: 35-60.

Nathan, M. (2013). Inicio de la fecundidad en mujeres de Montevideo y área metropolitana. ¿Postergación? ¿Polarización?. RELAP 7(12): 33-58.

Pardo, I. and Cabella, W. (2014). El descenso de la fecundidad en Uruguay (1996-2011) y el efecto tempo en las medidas sintéticas. Paper presented at the VI Congreso de la Asociación Latinoamericana de Población, Lima, Peru.

Peri, A. and Pardo, I. (2008). Nueva evidencia sobre la Hipótesis de la Doble Insatisfacción: ¿Cuán lejos estamos de que toda la fecundidad sea deseada? Serie Divulgación. Montevideo: UNFPA.

Rallu, L. and Toulemon, T. (1994). Period fertility measures. The construction of different indices and their application to France, 1946-89. Population, An English Selection 6: 59-94.

Rama, G. (1987). La democracia en Uruguay. Una perspectiva de interpretación. Buenos Aires: Grupo Editor Latinoamericano.

Rios-Neto, E. and Miranda-Ribeiro, A. (2015) Fertility Decline in Brazil: Tempo, Quantum and Parity Composition Effects. Paper presented at the Population Association of America, 2015 Annual Meeting, San Diego, CA.

Rodriguez, J. and Cavenaghi, S. (2013). Adolescent and youth fertility and social inequality in Latin America and the Caribbean: what role has education played? Paper presented at the XXVII IUSSP International Population Conference, 2013, Busan.

Rodriguez, J. (2014). Fecundidad adolescente en América Latina: una actualización. In: Cavenaghi, S. and Cabella, W. (eds.). Comportamiento reproductivo y fecundidad en América Latina: una agenda inconclusa. Rio de Janeiro: ALAP: $33-65$.

Rosero-Bixby, L., Castro-Martín, T., and Martín-García, T. (2009). Is Latin America starting to retreat from early and universal childbearing? Demographic Research 20(9): 169-194. doi:10.4054/DemRes.2009.20.9. 
Sullivan, R. (2005). The age pattern of first-birth rates among U.S. women: the bimodal 1990s. Demography 42(2): 259-273. doi:10.1353/dem.2005.0018.

United Nations (2014). World Urbanization Prospects. The 2014 Revision. New York: United Nations.

United Nations (2015). World Population Prospects. The 2015 Revision. New York: United Nations.

Varela, C, Fostik, A., and Pollero, R. (2008). La fecundidad: evolución y diferenciales en el comportamiento reproductivo. In: Varela, C. (ed.). Demografía de una sociedad en transición: la población uruguaya a inicios del siglo XX. Montevideo: Trilce.

Varela, C., Lara, C., Nathan, M., Pardo, I., and Tenenbaum, M. (2014). La fecundidad en el Uruguay (1996-2011). Desigualdad social y diferencias en el comportamiento reproductivo. Atlas Sociodemográfico y de la Desigualdad del Uruguay. Montevideo: Trilce.

Videgain, A.K. (2006). Análisis de los cambios en la transición a la adultez en mujeres de distintas cohortes en contexto de cambios sociales en el Uruguay contemporáneo [Master's Thesis]. México D.F.: El Colegio de México. 


\section{Appendix}

Figure A-1: Proportion of women by age and parity on Jan 1st, 2011, computed by two methods: extrapolation using 1996 census data with age- and parity-specific fertility rates for 1996-2010 (solid lines) versus 2011 census data (dotted lines)

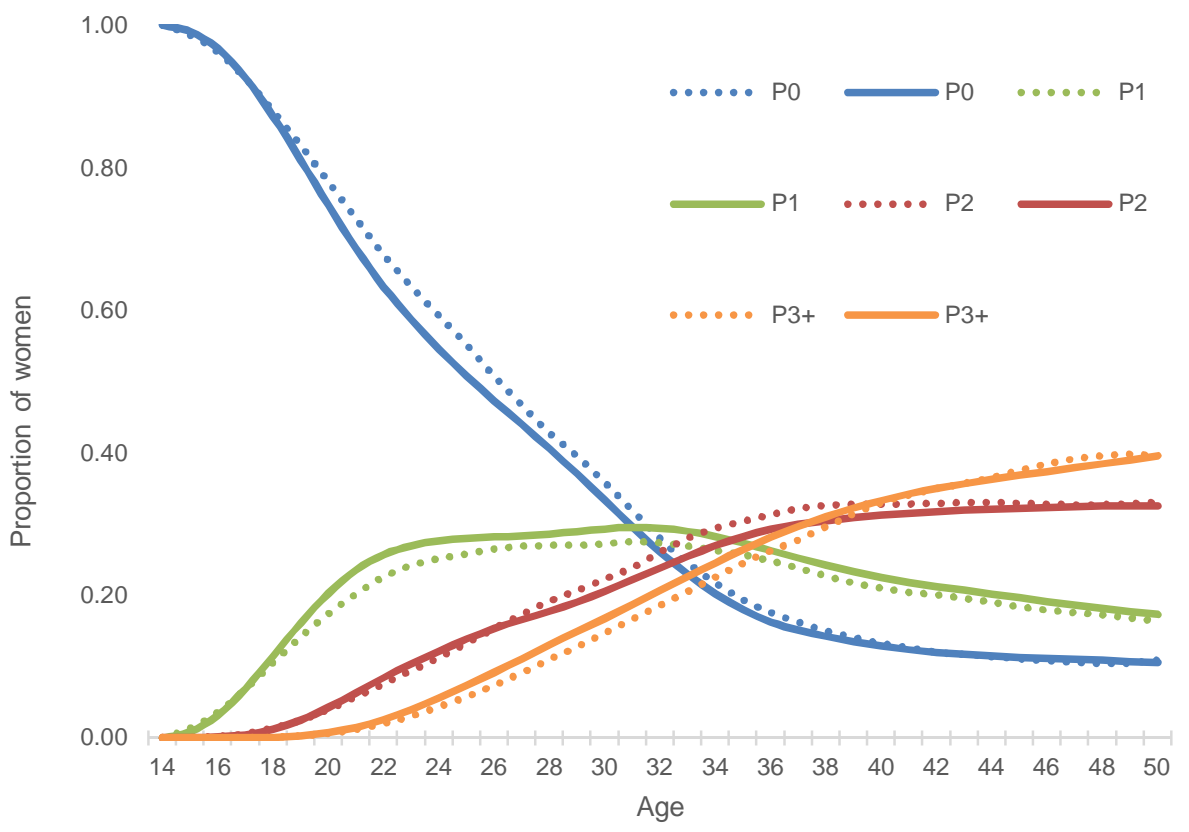

Source: authors' calculation based on Live-Birth Certificate, Perinatal Information System, 1996 and 2011 census, and official female population estimates by age. 